\title{
An Experimental Study of the Oxygen Permeability of a PET Film With a Nanosized Aluminum Oxide Layer
}

\author{
S. P. Korolev ${ }^{1}$, K. S. Kravchuk ${ }^{2}$, V. P. Panchenko ${ }^{3}$, L. A. Seidman ${ }^{4}$ \& A. M. Soroka ${ }^{1}$ \\ ${ }^{1}$ OOO BESEDY Innovation Industrial Complex, Moscow oblast, Russia \\ ${ }^{2}$ Technological Institute for Superhard and New Carbon Materials, Moscow, Russia \\ ${ }^{3}$ AO Troitsk Institute for Innovative and Fusion Research State Research Center of the Russian Federation, \\ Moscow, Russia; Bauman Moscow State Technical University, Moscow, Russia \\ ${ }^{4}$ OOO Laboratory of Vacuum Technologies, ELMA Technopark, Moscow, Russia \\ Correspondence: Panchenko Victor, ul. Tsentral'naya 14, 119, Troitsk, Moscow 108840, Russia. Tel: \\ 7-916-688-2375. E-mail: panchvictor@gmail.com
}

Received: January 13, 2022

doi:10.5539/apr.v14n1p8
Accepted: February 10, 2022

Online Published: February 21, 2022

URL: https://doi.org/10.5539/apr.v14n1p8

\begin{abstract}
Results of an experimental study of the oxygen permeability of a PET film with nanosized aluminum oxide layers formed by reactive magnetron sputtering have been described. An experimental dependence of the oxygen permeability coefficient of PET film with the aluminum oxide layer in the range of $20 \div 80 \mathrm{~nm}$, providing its value up to $1 \mathrm{~cm}^{3} /\left(\mathrm{m}^{2} \cdot 24 \mathrm{~h} \cdot 0.1 \mathrm{MPa}\right)$, have been determined. The effect of various factors on the formation of a high-quality reproducible oxide PET film and the characteristics of a nanosized aluminum oxide layer and the specific electric energy consumption for the magnetron deposition of the layer has been defined. The planar surface structures and surface roughness parameters of PET and oxide films with layers of different thicknesses have been determined. A qualitative interpretation of the results has been given.
\end{abstract}

Keywords: AFM image, aluminum oxide, film, magnetron sputtering, nanosized layer, oxygen, permeability, PET, surface, thickness

\section{Introduction}

A well-known and relevant method to decrease the gas and vapor permeability of polymer films is their coating with a dielectric layer of a metal oxide $\left(\mathrm{AlO}_{x}, \mathrm{SiO}_{x}, \mathrm{TiO}_{x}\right.$, etc.) of a nanoscale thickness (20-200 nm), which is deposited using various techniques (Zhang, Sang, Wang et al., 2018, Hirvikorpi, 2011, Lingle, 2014, Chang, Hou, Tsai \& Jhu, 2014). This nanosized coating changes the mechanism of permeation of molecules through the bilayer composition and provides a decrease in the gas and vapor permeability to a required level. The best barrier properties with respect to water vapors and oxygen are achieved in the case of deposition of an aluminum oxide layer on polymer films, in particular, a PET film (Zhang et al., 2018, Struller, C. F., Kelly, P. J., Copeland, N. J. et al., 2014, Carcia, P. F., McLean, R. S., Groner, M. D., et al., 2009).

An efficient method for depositing nanosized layers of metals and their oxides, in particular, aluminum oxide, is reactive magnetron sputtering, which provides a two orders of magnitude decrease oxygen permeability coefficient of PET (to $\approx 1 \mathrm{~cm}^{3} /\left(\mathrm{m}^{2} \cdot 24 \mathrm{~h} \cdot 0.1 \mathrm{MPa}\right.$ ) and of polypropylene films (to $\approx 7 \mathrm{~cm}^{3} /\left(\mathrm{m}^{2} \cdot 24 \mathrm{~h} \cdot 0.1 \mathrm{MPa}\right.$ ) (Berlin \& Seidman, 2014).

However, the quantitative dependence the coefficient of oxygen permeability through the PET film on the thickness of the nanosized layer of aluminum oxide and the conditions for obtaining a high-barrier oxide film of PET are absent in the scientific and technical literature.

Currently, both high-barrier films with oxygen permeability coefficient of no more than $3 \div 5 \mathrm{~cm}^{3} /\left(\mathrm{m}^{2} \cdot 24 \mathrm{~h} \cdot 0.1 \mathrm{MPa}\right)$ and ultra-high-barrier films with a coefficient of no more than $1 \mathrm{~cm}^{3} /\left(\mathrm{m}^{2} 24 \mathrm{~h} 0.1 \mathrm{MPa}\right)$ are in demand and produced on a large scale.

The aim of the study the results of which are described in this manuscript was to experimentally determine the dependence of oxygen permeability through a PET film with a nanosized aluminum oxide layer deposited by 
magnetron sputtering on the thickness of the oxide layer, the specific electric energy for the formation of the layer, the surface structure, and the roughness parameters and give a qualitative interpretations of the results obtained.

\section{Conditions for Preparing a PET Film With a Nanosized Aluminum Oxide Layer}

An oxide layer was deposited on a roll PET film substrate using a large-scale magnetron sputtering unit containing a pair of magnetrons equipped with $1400 \times 100 \times 10 \mathrm{~mm}^{3}$ aluminum targets. The vacuum system of the unit provided an ultimate vacuum in the working chamber of $1 \times 10^{-3} \mathrm{~Pa}$. The magnetrons were arranged adjacent to each other in vacuum chamber; they operated in the dual magnetron mode. The power supply of the magnetrons provided the feeding of packets of five pulses of an identical polarity at a frequency of $40 \mathrm{kHz}$ to each of the magnetrons in turn. The magnetrons operated at an argon pressure of $0.25 \mathrm{~Pa}$. A roll PET film with a thickness of $19 \mu \mathrm{m}$, a width of $1.2 \mathrm{~m}$, and a length of up to $2.5 \mathrm{~km}$, which was not exposed to a corona discharge (nonactivated), was used as the film substrate.

It is known that, to provide the formation of high-quality oxide polymer films, the surface of the film substrate should be treated before depositing an oxide layer (Berlin \& Seidman, 2014, Carcia et al., 2009, Struller et al., 2014).

Therefore, in the experiments, the roll PET film was pretreated with a magnetron discharge plasma. This pretreatment included the degassing and "cleaning" of the surface of the roll film, while moving it relative to the magnetron discharge plasma in an argon-nitrogen mixture at a ratio of $\mathrm{Ar}: \mathrm{N}_{2}=1: 3$ and at a total pressure of 0.25 $\mathrm{Pa}$. The magnetrons operated at a stabilized current of $10 \mathrm{~A}$ and a total discharge power of $2.5 \mathrm{~kW}$. The rate of movement of the PET film relative to the magnetrons was $2 \mathrm{~m} / \mathrm{min}$.

During this treatment, the magnetron discharge plasma heats the film surface and bombards it with ions, the energy of which is about $20 \mathrm{eV}$. The result is the desorption of atoms and molecules of hydrogen, nitrogen, oxygen, water, and organic substances from the surface.

After "cleaning" of the substrate, the supply of nitrogen was stopped, while the supply of argon to the chamber was increased to a pressure of $0.25 \mathrm{~Pa}$. Next, the surfaces of the aluminum targets were "cleaned" from aluminum oxides under a magnetron discharge in argon in the current stabilization mode (rewinding of the film roll in the opposite direction).

After that, to deposit an oxide layer during the rewinding of the roll film at a given rate, the power supplies were switched to the voltage stabilization mode and oxygen was fed; the oxygen flow rate was gradually increased until the discharge current achieved a maximum value for the power supply. In this mode, the discharge voltage was 400 $\mathrm{V}$, and the discharge current per pulse achieved $15 \mathrm{~A}$ at an oxygen flow rate of $0.4 \mathrm{~L} / \mathrm{h}$ and a total gas pressure in the chamber of $0.25 \mathrm{~Pa}$. Under these conditions, owing to oxygen absorption by the growing oxide layer, the partial pressure of oxygen in the gas mixture did not exceed $0.25 \mathrm{mPa}$, and the density of the flux of aluminum atoms to the surface achieved $6 \times 10^{19} \mathrm{~m}^{-2} \mathrm{~s}^{-1}$. The current density of argon and oxygen ions from the plasma on the target and film surfaces was $45 \mathrm{~A} / \mathrm{m}^{2}$.

To deposit an aluminum oxide layer of a required thickness, the roll PET film was repeatedly rewound in both directions. The effective rate of movement of the PET film substrate (deposition time) was set in a range of 0.3-2 $\mathrm{m} / \mathrm{min}$, while accordingly changing the number of rewinds $N$ of the roll film $(N=1-6)$; this condition provided the thickness of the oxide layer in a range of $20 \div 120 \mathrm{~nm}$. The aluminum oxide film grown in these modes was completely transparent; this fact suggests that the film composition is nearly stoichiometric. Thus, the pretreatment of the PET film and the reactive magnetron sputtering of an aluminum oxide layer on it were conducted in a continuous process and on the same unit.

To measure the thickness of the oxide layer, four aluminum oxide layers were successively deposited on the roll film with a 450- $\mu \mathrm{m}$-thick silicon wafer fixed on it, while rewinding the roll film in the forward and reverse direction. After the deposition of the oxide layer, a sample with the wafer was cut from the film; the oxide layer portions localized on the strips of the photoresist mask were removed from the wafer by washing. As a consequence, several ledges ("steps") were formed in the cross-sectional topography of the wafer; the height of the steps was equal to the thickness of the oxide layer. To increase the contrast and improve the measurement accuracy, an aluminum layer with a thickness of 200-300 nm was deposited on the wafer on a laboratory magnetron sputtering unit.

The average thickness of the oxide layer was measured in accordance with a refined procedure using a measuring setup based on a Zygo Nev View 7300 high-resolution interferometer (Kuchin \& Obradovich, 1981). The height of the step and, accordingly, the thickness of the deposited layer were determined by photometry and processing of 
interferograms of the wafer with stripes of the oxide layer. The instrumental error of this measuring device does not exceed $\pm 2 \%$ of the thickness of the measured coating layer (Kuchin, 1981).

It was assumed that, despite the different states of the substrate during the deposition of oxide layers, particularly the first layer, the effective thickness (average over the sample area) of each layer deposited during one rewinding of the film roll is $1 / N$ of the total thickness of the layer deposited during $N$ rewinds.

The results of the measurements of the arithmetic mean values of the thicknesses of the aluminum oxide layers are shown in the table.

Table 1. Experimental values of the main parameters of a PET film with a nanosized aluminum oxide layer

\begin{tabular}{ccccc}
\hline $\begin{array}{l}\text { Sample } \\
\text { number }\end{array}$ & $\begin{array}{l}\text { Average thickness } \\
\text { of the oxide layer, } \\
\mathrm{nm}\end{array}$ & $\begin{array}{l}\text { Effective } \\
\text { unwinding speed } \\
\text { of the film, } \\
\mathrm{m} / \mathrm{min}\end{array}$ & $\begin{array}{l}\text { Specific specific } \\
\text { electric energy for } \\
\text { nanosized layer } \\
\text { deposition, } \times 10^{-5}, \mathrm{~J} / \mathrm{m}^{2}\end{array}$ & $\begin{array}{l}\text { Average oxygen } \\
\text { permeability } \\
\text { coefficient value, } \\
\mathrm{cm}^{3} /\left(\mathrm{m}^{2} \cdot 24 \mathrm{~h} \cdot 0.1 \mathrm{MPa}\right)\end{array}$ \\
\hline 1 (PET) & 0 & - & - & 241 \\
\hline 2 & $20.1 \pm 0.4$ & 2.20 & 2.40 & 4.06 \\
\hline 3 & $40.3 \pm 0.8$ & 1.10 & 4.80 & 1.90 \\
\hline 4 & $60.4 \pm 1.2$ & 0.73 & 7.20 & 1.39 \\
\hline 5 & $80.6 \pm 1.6$ & 0.55 & 9.60 & 1.02 \\
\hline
\end{tabular}

\section{Oxygen Permeability Coefficient of a PET Film With a Nanosized Aluminum Oxide Layer}

The oxygen permeability coefficient $J\left[\mathrm{~cm}^{3} /\left(\mathrm{m}^{2} \cdot 24 \mathrm{~h} \cdot 0.1 \mathrm{MPa}\right)\right]$ of PET film and aluminum oxide film samples was measured on a LABTHINK Instruments VAC-V1 system (Anonymous, 2019). The instrumental error in measuring the oxygen permeability coefficient does not exceed $\pm 3 \%$. The measurements were conducted using samples with a diameter of $70 \mathrm{~mm}$ at a temperature of $30^{\circ} \mathrm{C}$ under thermostatting conditions for $24 \mathrm{~h}$.

The results of measurements of the oxygen permeability coefficient of the aluminum oxide film are shown in the table; the dependence of the reciprocal of permeability $1 / J$ on the average thickness of the aluminum oxide layer $\langle\delta\rangle$ is shown in Figure 1. Note that the permeability at a level of $1 \mathrm{~cm}^{3} /\left(\mathrm{m}^{2} \cdot 24 \mathrm{~h} \cdot 0.1 \mathrm{MPa}\right)$, that is, at a layer thickness of $\approx 40 \mathrm{~nm}$, meets most of the technical requirements for high-barrier packaging.

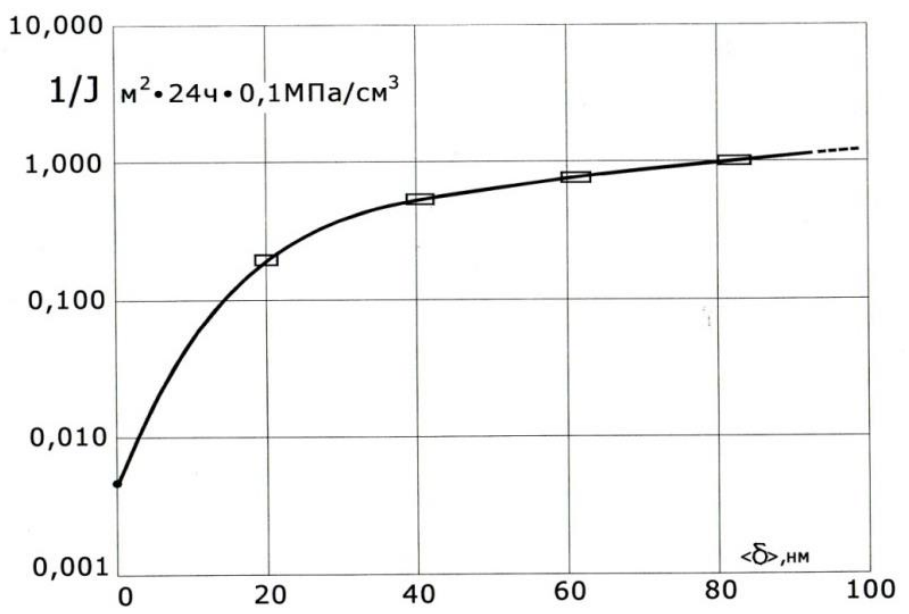

Figure 1. Dependence of the reciprocal of the oxygen permeability coefficient of an oxide film of PET on the thickness of the aluminum oxide layer

Key:

$\mathrm{m}^{2} \cdot 24 \mathrm{q} \cdot 0,1 \mathrm{M} \Pi \mathrm{a} / \mathrm{cm}^{3} \rightarrow \mathrm{m}^{2} \cdot 24 \mathrm{~h} \cdot 0.1 \mathrm{MPa} / \mathrm{cm}^{3}$

HM $\rightarrow$ nm 
To determine the oxygen permeation mechanism and the surface structure, the surfaces of the PET film and oxide aluminum oxide layers of various thicknesses on it were recoded on an NTEGRA Prima atomic force microscope (AFM).

Figure 2 shows a planar AFM image of the surface of a PET film sample; Figures 3 and 4 show the surfaces of a composition with aluminum oxide layers with an average thickness of $20.1 \mathrm{~nm}$ and $40.3 \mathrm{~nm}$, respectively.

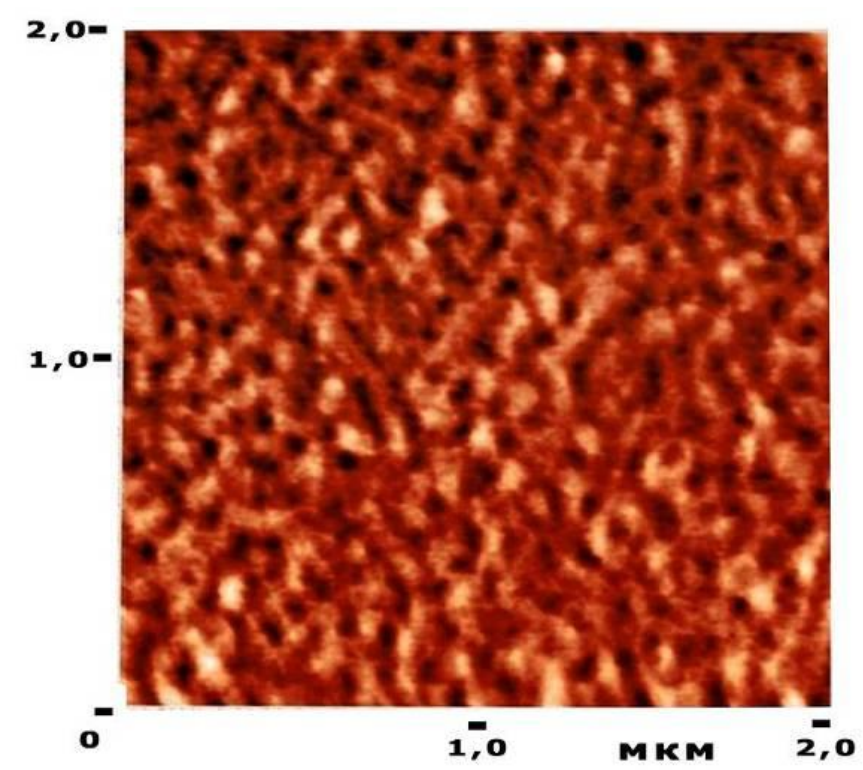

Figure 2. Planar AFM image of a surface region of the PET film: degree of surface porosity, $\approx 6 \%$; length of surface pores, $20-100 \mathrm{~nm}$; width, $20-40 \mathrm{~nm}$; and roughness scale factor, $\approx 2 \mathrm{~nm}$.

Kеу: мкм $\rightarrow \mu \mathrm{m}$

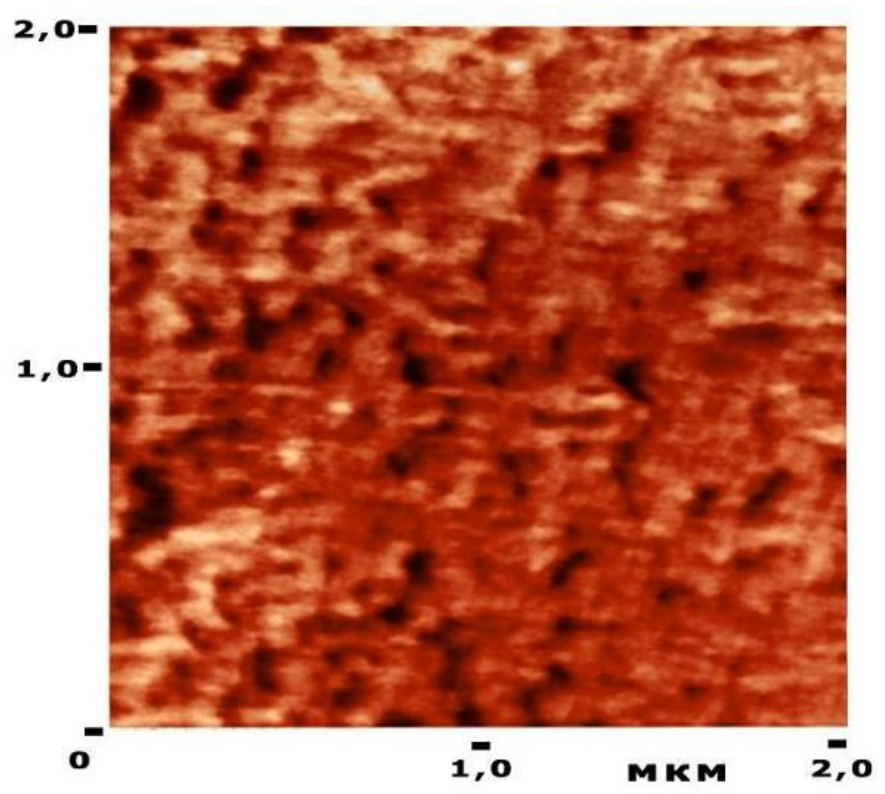

Figure 3. Planar AFM image of a surface region with an aluminum oxide layer with an average thickness of 20.1 $\mathrm{nm}$ : degree of surface porosity, $\approx 2 \%$; length of surface pores, $50-100 \mathrm{~nm}$; width, $40-50 \mathrm{~nm}$; and roughness scale factor, $\approx 7 \mathrm{~nm}$.

Keу: мкм $\rightarrow \mu \mathrm{m}$ 


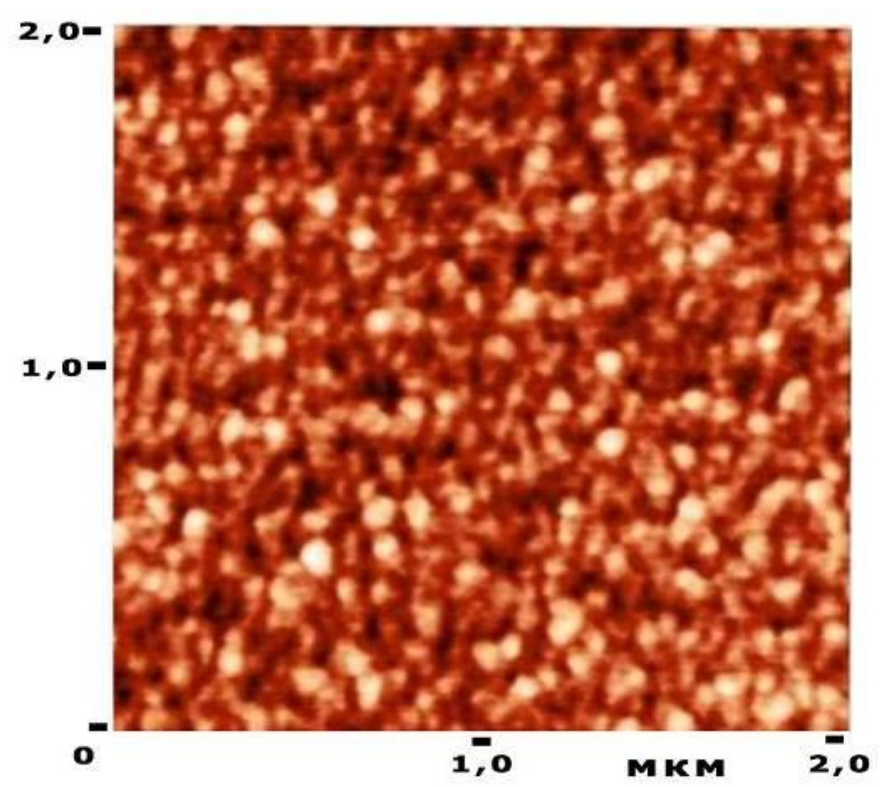

Figure 4. Planar AFM image of a surface region with an aluminum oxide layer with an average thickness of 40.3 $\mathrm{nm}$ : porosity, a few fractions of a percent; characteristic size of inhomogeneities, $\approx 70 \mathrm{~nm}$, and roughness scale factor, $\approx 3 \mathrm{~nm}$.

Key:

мкм $\rightarrow \mu \mathrm{m}$

It was assumed that the deep valleys in the planar surface image (black areas) represent pore mouths. According to computer-aided visual processing, in this case, the surface of the PET film substrate has a degree of porosity of $\approx 6 \%$; irregularly shaped elongated valleys with a length of $20-100 \mathrm{~nm}$ and a width of $30-40 \mathrm{~nm}$ are randomly located on the surface (Figure 2). The degree of surface porosity was determined as the ratio of the total area of pore mouths to the area of the studied film region with a size of $2 \times 2 \mu \mathrm{m}$. The roughness parameters had the following values: $R_{\mathrm{a}}=0.23 \mathrm{~nm}, R_{\mathrm{z}}=1.66 \mathrm{~nm}$, and $S_{\mathrm{m}}=158 \mathrm{~nm}$.

The measured oxygen permeability coefficient values of the PET film samples untreated with a corona discharge $\left(\approx 240 \mathrm{~cm}^{3} /\left(\mathrm{m}^{2} \cdot 24 \mathrm{~h} \cdot 0.1 \mathrm{MPa}\right)\right)$ are significantly higher (by $2 \div 4$ times) than the reported values of $50-150$ $\mathrm{cm}^{3} /\left(\mathrm{m}^{2} \cdot 24 \mathrm{~h} \cdot 0.1 \mathrm{MPa}\right)$ (Lingle, 2014, Chang et al., 2014, Struller et al., 2014, Carcia et al., 2009). This fact is attributed to the film growth procedure, which leads to the formation of a certain number of through and/or deep curvilinear pores with a variable cross-sectional area, the number of calibers of which exceeds 100, and a transient mode of flow of oxygen molecules in them owing to a pressure gradient at a Knudsen number of Kn $\sim 1$ (free path of oxygen molecules is $\approx 70 \mathrm{~nm}$ ).

The deposition of an aluminum oxide layer with an average thickness of $\approx 20 \mathrm{~nm}$ leads to a decrease in the degree of surface porosity by $\approx 3$ times (to $\approx 2 \%$ ). At the same time, most of the pores observed on the surface are large pores with a length of $50-100 \mathrm{~nm}$ and a width of $\approx 40 \mathrm{~nm}$ (Figure 3 ). The surface roughness of the oxide layer is significantly higher than that of the PET film: it is $R_{\mathrm{a}}=0.95 \mathrm{~nm}, R_{\mathrm{z}}=7.03 \mathrm{~nm}$, and $S_{\mathrm{m}}=170 \mathrm{~nm}$. Nevertheless, the oxygen permeability coefficient abruptly decreases 60 -fold (to $\approx 4 \mathrm{~cm}^{3} /\left(\mathrm{m}^{2} 24 \mathrm{~h} 0.1 \mathrm{MPa}\right)$ ) (Fig. 1).

This effect can be attributed to the adsorption of "hot" aluminum atoms, their incorporation into the surface layer of the PET film (approach atom velocity, $\approx 10^{4} \mathrm{~m} / \mathrm{s}$; atom diameter, $0.12 \mathrm{~nm}$ ), their penetration into the initial portions of the pores, and the formation of - primarily - $\mathrm{AlO}_{x}$ oxide molecules and then - from the molecules agglomerates (clusters). The result is the formation of an uneven coating of the film surface and a partial or complete (for small pores) closure of the pore mouths, which leads to a qualitative change in the mechanism of permeation of oxygen molecules through the film of the bilayer composition.

At an oxide layer thickness of $\geq 40 \mathrm{~nm}$ (Figure 4), a continuous aluminum oxide layer is formed on the film surface (for a 40-nm-thick layer, the porosity is a few fractions of a percent) and almost all the mouths of the PET film pores are closed, while the oxygen permeability coefficient of the oxide film decreases by two orders of magnitude compared with the permeability of the film without an oxide layer (Figure 1). In this case, the surface topography 
of the oxide layers remains similar to that shown in Figure 5 for a 40.3 -nm-thick layer, while the surface roughness of the oxide film decreases $\left(R_{\mathrm{a}}=0.33 \mathrm{~nm}, R_{\mathrm{z}}=2.45 \mathrm{~nm}, S_{\mathrm{m}}=211 \mathrm{~nm}\right.$ at a thickness of $\left.40.3 \mathrm{~nm}\right)$ and approaches the roughness of the PET film. With a further increase in the thickness of the oxide layer, the permeability of the film decreases further, yet slightly in this case (by $\approx 1.3$ times with an increase in the layer thickness from 60 to $100 \mathrm{~nm}$ ); this fact suggests that permeation mostly occurs by the diffusive mechanism (Figure 1).

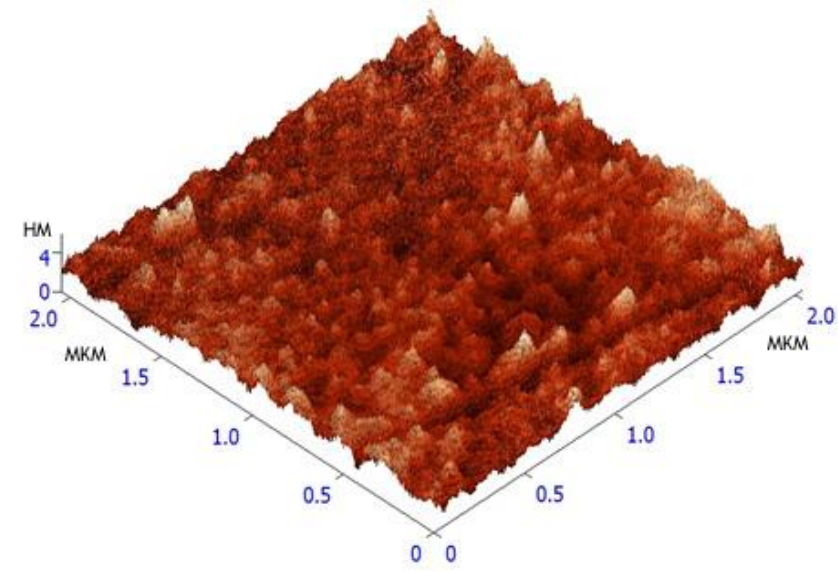

Figure 5. Surface relief of an aluminum oxide layer $40.3 \mathrm{~nm}$ thick on a PET film

Key:

мКм $\rightarrow \mu \mathrm{m} /$ нм $\rightarrow \mathrm{nm}$

A confirmation of the absence of a metallic phase in the composition of the aluminum oxide layers on a PET film was the high transparency of the bilayer film and the absence of electrical conductivity and heating under microwave radiation.

Note that the dependence of the oxygen permeability coefficient of a polyester (PLA) film on the thickness of an aluminum oxide layer deposited by atomic layer deposition (ALD technology) exhibits a similar behavior (Hirvikorpi, 2011).

The obtained experimental data were used to determine the specific electric energy consumption for the preparation of a unit area of an oxide film of a required thickness per unit of time: $q=N_{\mathrm{e}} /\left(v^{*} \times b\right)\left[\mathrm{J} / \mathrm{m}^{2}\right]$, where $N_{\mathrm{e}}$ $=V_{\mathrm{m}} \times I_{\mathrm{m}}$ is the electric power consumed by magnetrons, $b=1000 \mathrm{~mm}$ is the width of the roll film, and $v^{*}$ is the effective unwinding speed. For the deposition conditions at electric power of magnetron $N_{\mathrm{e}}=8.8 \mathrm{~kW}$ (current of 22 A), the specific consumptions for various thicknesses of aluminum oxide layers are listed in the table; they have a value of $\approx 5 \times 10^{5} \mathrm{~J} / \mathrm{m}^{2}$ characteristic of a high-barrier oxide film.

\section{Conclusion}

The following results have been obtained in this study:

(i) A mechanism for a qualitative decrease in the coefficient of oxygen permeability through a PET film during magnetron sputtering of an aluminum oxide layer was established, which consists in closing the inlets of its nanosized pores;

(ii) The method of magnetron sputtering was used to obtain an experimental dependence of the permeability coefficient of a PET film on the thickness of a nanoscale aluminum oxide layer in the range of $20 \mathrm{~nm}-80 \mathrm{~nm}$, which has an essentially non-linear character;

(iii) Under the experimental conditions and the quality of the original PET film to obtain a high-barrier PET film with a permeability coefficient relative to oxygen $\leq 2 \mathrm{~cm}^{3} /\left(\mathrm{m}^{2} \cdot 24 \mathrm{~h} \cdot 0.1 \mathrm{MPa}\right)$, the thickness of the oxide layer should be $\geq 40 \mathrm{~nm}$;

(iv) The need for preliminary plasma treatment of the surface of the initial PET film by magnetron sputtering was experimentally proved to obtain a high-barrier film with a nanoscale layer of aluminum oxide.

The obtained experimental data and their analysis suggest that, in the case of magnetron sputtering of an aluminum oxide layer onto other types of polymer films, the necessary thickness of the nanoscale layer, which provides high 
barrier properties against gases and vapors, should be on the order of the characteristic dimensions of the input pore sizes on their surfaces.

In this case, to determine the required thickness of the aluminum oxide layer, it is sufficient to measure the characteristic size of the input pore sizes. However, to confirm the proposed assumption, an experimental study of the oxygen (or other gases) permeability in other types of polymer films is required.

\section{Acknowledgments}

This work was supported in part by the Foundation for Promotion of the Development of Small Business in Science and Technology in Russia, project no.10474r/19532 of June 4, 2015

\section{References}

Berlin, E. V., \& Seidman, L. A. (2014). Thin Film Growth by Reactive Magnetron Sputtering. Tekhnosfera, Moscow. [in Russian]

Carcia, P. F., McLean, R. S., Groner, M. D., et al. (2009). Gas diffusion ultrabarriers on polymer substrates using $\mathrm{Al}_{2} \mathrm{O}_{3}$ atomic layer deposition and $\mathrm{SiN}$ plasma-enhanced chemical vapor deposition, J. Appl. Phys., 106, 023533. https://doi.org/10.1063/1.3159639

Chang, R. C., Hou, H. T., Tsai, F. T., \& Jhu, P. S. (2014). Atomic layer deposited $\mathrm{Al}_{2} \mathrm{O}_{3}$ barrier layers on flexible PET substrates. Appl. Mech. Mater, 479-480, 80-85.

Hirvikorpi, T. (2011). Thin $\mathrm{Al}_{2} \mathrm{O}_{3}$ barrier coating grown on bio-based puckering materials by atomic layer deposition, Diss. VTT Publication (Finland), Sept. 2011. Retrieved June 21, 2020, from http//www.vitt.fi/inf/pdf/publication/2011/P770.pdf

Kuchin, A. A., \& Obradovich, K. A. (1981). Optical Instruments for Measuring Surface Roughness. Mashinostroenie, Leningrad. [in Russian]

Lingle, R. (2014). Super-barrier nanofilm stretches packaging applications: Single nanolayer on PET in Packaging Digest, August 12. Retrieved March 25, 2021, from www.packagingdigest.com

Struller, C. F., Kelly, P. J., Copeland, N. J. et al.. (2014). Aluminum oxide barrier films on polymeric web and their conversion for packaging applications. Thin Solid Films, 553, 153-156.

VAC-V1 Gas Permeability Measurement Device. Labthink Instruments Co., Ltd. Retrieved December 15, 2019, from directindustry.com.ru/prod/labthink-instruments-co-ltd/product-58198-824083.html

Zhang, H., Sang, L., Wang, Z., et al. (2018). Recent progress on non-thermal plasma technology for high barrier layer fabrication. Plasma Sci. Technol., 20, 1-16.

\section{Copyrights}

Copyright for this article is retained by the author(s), with first publication rights granted to the journal.

This is an open-access article distributed under the terms and conditions of the Creative Commons Attribution license (http://creativecommons.org/licenses/by/4.0/). 